\title{
Implementation of a New Geometrical Qualification (DQ) Method for an Open Access Fused Filament Fabrication 3D Printer
}

\author{
Boumediene Belarbi \\ Electrical Engineering Department, \\ University of Abu Bekr Belkaid, \\ Tlemcen, Algeria \\ belarbi_boumediene@yahoo.fr
}

\author{
Mohamed el Amine Ghernaout \\ Mechanical Engineering Department, \\ University of Abu Bekr Belkaid, \\ Tlemcen, Algeria \\ mea_ghernaout@mail.univ-tlemcen.dz
}

\author{
Tawfik Benabdallah \\ Mechanical Engineering Department, \\ National Polytechnic School (ENP), \\ Algiers, Algeria \\ tawfikbenabdallah@yahoo.fr
}

\begin{abstract}
This work presents geometric qualification on rapid prototyping process in the case of open access $3 D$ printers where a working model is proposed and a prototype measurement is presented. The problem, which is to develop a methodological approach for the realization of five test pieces of equal dimensions based on complete process knowledge of the downstream material deposit movement according to XML standards, is addressed after a state of the art review. The result allows confirming the quality of the machine recommended by the manufacturer. Basically, the adopted methodology was used to fill the vacuum in the 3D FDM (open source) 3D geometric qualification (DQ) as well as to pave the way for the 3D printing processes standardization [1].
\end{abstract}

Keywords-qualification; 3D; part test, quality; insurance; rapid prototyping; geometry

\section{INTRODUCTION}

Often small and medium-sized enterprises (SMEs) use lowcost, open access printers, which make the cost of research and development low. It is difficult to check if the designer's data conform to the manufacturer's specifications. Therefore, it is necessary to develop a machine qualification methodology and product test. The prototype model is inevitable in the development phase, that's why the research problem lies in the fact of how to qualify 3D printing processes realized in open source (Figure 1) [1]. Manufacturing consists of an iterative ratio of material (point by point and layer by layer) according to the different forms of the parts, whereas in the machining techniques we proceed by removing material (subtractive process).This work is concerned with the qualification of rapid prototyping processes (Figure 2) [1]. Therefore, a real industrial need was met, following a qualification procedure and standards adapted to 3D printers (Figure 3).

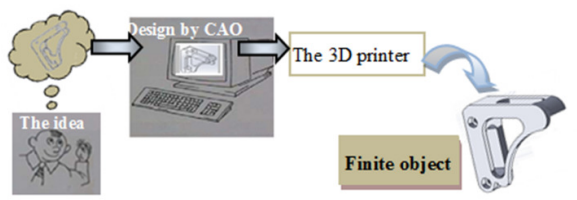

Fig. 1. The flux of rapid prototyping process
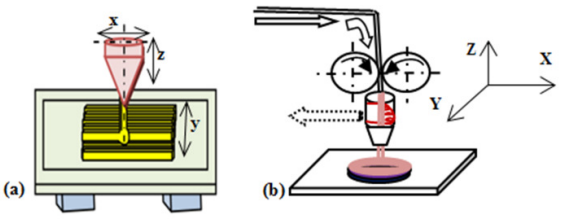

Fig. 2. (a) Process of $x x x 3 D$ printer, (b) Deposition of molten wire (FDM)

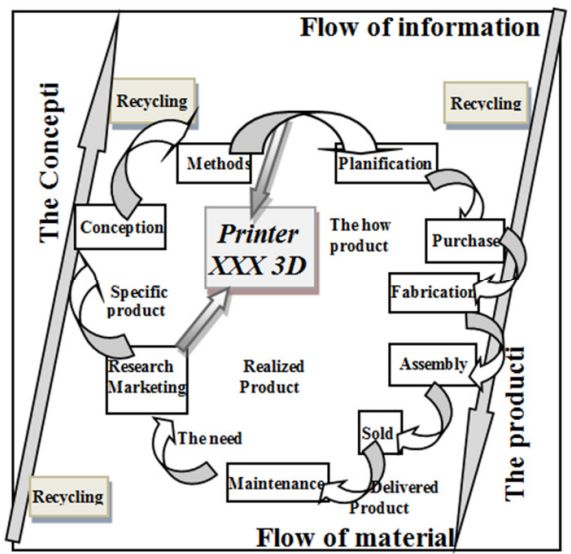

Fig. 3. Cycle of product development (xxx3D)

\section{PROBLEM STATEMENT}

Qualification process is crucial to quantify influences of each factor and is achieved with checking the data of the designer with the manufacturer's specifications. In this study, only the additive processes FDM, laser polymerization, stereo lithography (STL), manufacturing by point-by-point/layer by layer, and material projection are tackled. It is noted that metrology is interested in the quality of measurements by various methods that complete qualification. Moreover, the control of the surface state and all its complex shapes obtained by $3 \mathrm{D}$ printing must constitute in the third level of the qualification action where the product conformity and its quality improvement are allowed by geometric metrology. 


\section{STATE OF THE ART REVIEW}

The basic approach to rapid prototyping can be described by a model or a component modeled on a CAD/CAM system, the assembly is represented according to a $3 \mathrm{D}$ model [2] in Figure 4. This work aims at laying the foundations of a qualification methodology that fills the gap since there are no references related to the qualification of low-cost open access (LCOA) 3D printers, with the exception of two contributions of the authors of this paper [1].

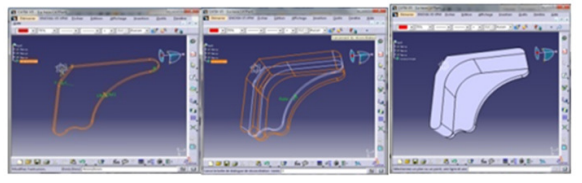

Fig. 4. Basis for rapid prototyping (std. part: motorcycle housing)

\section{Methodology}

One should refer to the three approaches forming the verification triangle (Figure 5).

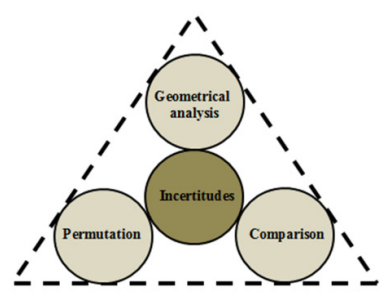

Fig. 5. Three methods for the verification triangle [3]

- Study of the machine geometry, probe behavior and different analytical approaches with precise experiments to integrate the uncertainties calculation.

- Performing an estimate to separate the input of all fixed errors. The approach for thermal phenomena embodied in the removal and pile-up of the raw material.

- A comparison between the value of the measurements taken and those given by the manufacturer (true values or standard measurements) [4].

Metrology allows us to analyze and verify the results obtained by carrying out an analysis between the specifications and the obtained results, as it is shown in the procedural flowchart in Figure 6.

\section{A. Application (Implementation)}

The qualification procedure consists of taking measurements on the test pieces (prototypes) and analyzing the results. Computer-aided construction (CAD) generates an STL file that represents its digital definition, hence the boundaries of the quality process. Besides, the qualification procedure must set the parameters of the production conditions, while considering the imposed post-processing (finalization, polymerization), the movement of the machine according to the XY plane (2D) by stepper motors, servo-control and measuring system and the 3rd Z-axis (3D). Moreover, this study evaluates the layer's thickness and smoothness of the device (displacement perpendicular to $\mathrm{X}$ and $\mathrm{Y}$ ), the speed of movement which is either straight or cylindrical confronted to the material behavior (deposition, connection of the preceding layer and cooling rate with shrinkage).

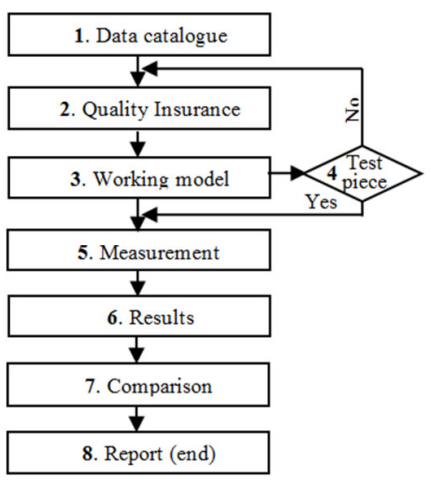

Fig. 6. Theoretical description of the qualifying process

\section{B. Qualification of the Printer Process}

However, quality is not considered the maximum performance, but the respect of the performance specified by the contract of realization. In order to qualify the process (FDM) and the printer, tests were carried out on measurements of certain functional ribs of the prototype

\section{QUALIFICATION TASK PROCEDURE}

Data collection was conducted through the following procedure:

- Data catalog: The qualification relates to a series printer taken randomly from a batch manufactured on a given date. The data will be collected directly from the catalogue, accompanying the machine in paper or electronic form.

- Quality insurance [5]: Quality assurance requires the mastery of the FDM process, hence the need to guide the development of the procedure for rapid prototyping qualification by the verification of conformity with an existing adapted standard. The most used ISO models in qualification are: 9000, 9001, 9002, 9003, 9004 and 14001. After evaluation of this conformity, a decision has been made on the recognition of the process suitability of a production line, a supplier, a component, etc.

- Working model: Measurements should be made in the laboratory with means that should be adapted to the characteristics covered by the qualification procedure. The ambient conditions (temperature of reference $20^{\circ} \pm 1^{\circ} \mathrm{C}$, relative humidity $55 \%$ and pressure $101325 \mathrm{~Pa}$ ) must be monitored. Variations affect the expansion of certain plastic materials which may affect the dimensions of the part.

- Test piece: The test piece is described with its design and material. It is a protective chain cover of a sport bike, made on a $3 \mathrm{D}$ printer based on $\mathrm{ABS}$. It does not require posttreatment or manual intervention or supports to facilitate its control and to deduce the origin of its defects. 
- Measurement: Measurements were carried out on all dimensions, verifying the compliances contained in the designer (manufacturer) specification book. Metrology is an integral part of the early stages of designing the production process and verifying alternatives to product solutions. Considering the importance of the measurement errors' influence on the precision of the parts and their valued measurements, a three-dimensional measuring device was used.

- Treatment of results: The determination of the statistical uncertainty of the quantities is performed by measuring the test piece deviations with the three-dimensional measuring machine (TMM). The 3D printer's deviations and the errors were measured, the part's statistical series and arithmetic averages were calculated. After verification, the deviation of these values became very small compared to the conditions recommended by the designer. Finally, it has been concluded that these values were within the tolerance interval imposed by the designer.

- Comparison and validation: It is required to make a comparison between theory and the results of the different points of the qualification process. A validation of these results is provided below. Determination of uncertainty requires that a series of measurements are made on the same part from which a full-scale statistics is drawn.

- Report (end): Once the qualification procedure is done, a final report should be released which must decide on the acceptance of the FDM printer qualification. The product is accepted for printing multiple plastic prototypes. Therefore, the obtained results lead in the acceptance of the $3 \mathrm{D}$ printer qualification, after verification.

\section{A. Environment}

It should be noted that the geometrical measurements and those of the metrology laboratory must be adapted to the characteristics of the concerned means. The ambient conditions must be monitored. Variations affect the expansion of certain plastic materials and affect the part's shape.

\section{B. Test Piece Description}

A motorcycle chain cover was chosen, made on the open source LCOA 3D ABS-based printer, based on simple geometric shapes allowing differentiation of the origin of the defect on the part upon which the test is conducted. It does not require post treatment, manual intervention or media. Moreover, a synthesis of the shapes which are to be joined makes it possible to define it completely (Figure 7).

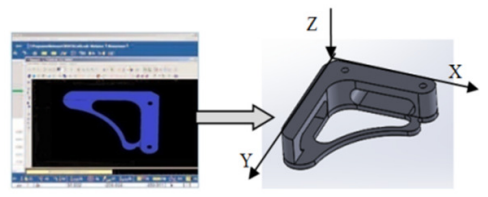

(a)

(b)

Fig. 7. (a) Test piece defined by CAO, (b) Piece obtained by xxx3D

\section{Test Piece Positioning (TPP)}

The positioning of the test piece on the $3 \mathrm{D}$ measuring machine (TMM) requires the following specifications on the software (CAD) [6]: The minimum number of points to position is 3 (flat support) (Figure 8), the functional dimensions are selected and their probing system is defined [2]. Then, they are decomposed with simple geometric elements (Figure 9). The $3 \mathrm{D}$ printer specifications given by the manufacturer are illustrated in Table I before the start of the measurements.

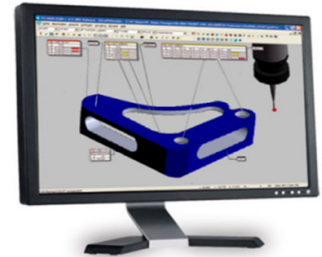

Fig. 8. Position of the test piece relative to the MMT probe

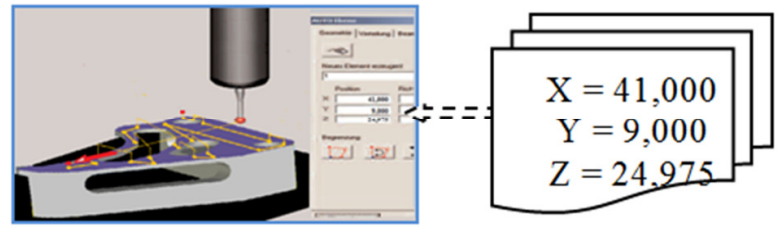

Fig. 9. The test piece control operation on the MMT.

TABLE I. THE XXX3D PRINTER CHARACTERISTICS [7]

\begin{tabular}{|c|c|}
\hline \multicolumn{2}{|c|}{ Measures and Dimensions } \\
\hline Width & $480 \mathrm{~mm}$ \\
\hline Length & $455 \mathrm{~mm}$ \\
\hline Including height & $455 \mathrm{~mm}$ \\
\hline Weight & $14 \mathrm{~kg}$ \\
\hline Temperature extruded & $270^{\circ} \mathrm{C}$ (s/type of filament) \\
\hline Print Volume & $230 \mathrm{~mm} \times 210 \mathrm{~mm} \times 190 \mathrm{~mm}$ \\
\hline Maximum print speed & $15 \mathrm{~mm}^{3} / \mathrm{s}$ and $50 \mathrm{~mm} / \mathrm{min}$ \\
\hline Movement X-Y & 50microns, \\
\hline Minimum print thickness $(\mathrm{Z})$ & 100microns \\
\hline Materials & PLA, ABS, Nylon, Lay Wd \&Brick \\
\hline Nozzle diameter & $0.4 \mathrm{~mm}$ \\
\hline Filament diameter & $3 \mathrm{~mm}$ \\
\hline Steering and connectivity & USB and Carte SD \\
\hline System Compatibility & Windows, Mac, Linux \\
\hline Alimentation & $110-220 \mathrm{~V}, 50-60 \mathrm{~Hz}$ \\
\hline
\end{tabular}

\section{Running a Measuring Range}

The correlation matrix indicates the link between measures and the influence factor with analysis of interactions. The geometric control considered is explained by the researchers' contribution with the study of the product "cache carter". Table II lists the different test pieces obtained, referring to the conditions imposed on the definition drawing by the design office. This work showed more accuracy and conformity with the definition drawing.

\section{E. Verification of the Geometric Specifications}

The parts must respect a minimum geometric tolerance. There are several types of apparatus, such as those used to characterize straightness, flatness, circularity, parallelism and 
perpendicularity. The tolerance interval imposed is $0.1 \mathrm{~mm}$ for all cases of this study. To do this, the computer tool CAD was chosen for the design of the decision support program. The treatment was performed by comparing the theoretical and measured results. Some measurements allow quantification of single defect, but analysis made it possible to determine more generally the defects of machine or material origin. Thus, the exploitation of all the collected information enabled identifying the sources of the defects influencing factors on the matrix. The use of the test pieces ensures the implementation of a correlation matrix. This, with the analysis of the interactions, helps list the measurements to be made and link between observations. The parameters related to the final prototype are taken into account [9]. The aim was to complement the correlation matrix for the geometric control of the test piece (realized on the 3D printer, by FDM=FFF).

TABLE I. CORRELATION MATRIX REDUCED FOR DIMENSIONAL INSPECTION [8]

\begin{tabular}{|c|c|c|c|c|c|c|c|c|c|c|}
\hline $\begin{array}{r}\text { Parameter } \\
\text { Process }\end{array}$ & 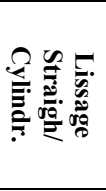 & 希 & $\stackrel{\prec}{\emptyset}$ & $\begin{array}{l}x \\
\underset{0}{0} \\
\stackrel{\theta}{=}\end{array}$ & $\underset{\swarrow}{\check{c}}$ & $\begin{array}{l}\mathbf{N} \\
\stackrel{\nabla}{\underline{\theta}} \\
\stackrel{=}{=}\end{array}$ & & 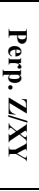 & $\begin{array}{l}\frac{7}{2} \\
\frac{2}{2} \\
\frac{x}{2}\end{array}$ & 产 \\
\hline $\begin{array}{c}\text { Parall.plan perp.to } \\
\mathrm{X} \text { measure } \\
\text { according } \mathrm{Z}\end{array}$ & & $\otimes$ & & & & & & & & \\
\hline $\begin{array}{c}\text { Parall.plan perp.to } \\
\text { Y measure } \\
\text { according } Z\end{array}$ & & & $\otimes$ & & & & & & & \\
\hline $\begin{array}{c}\text { Straightness XZ } \\
\text { according X }\end{array}$ & & $\otimes$ & & $\otimes$ & & $\otimes$ & & & & \\
\hline $\begin{array}{c}\text { Straightness YZ } \\
\text { according Y }\end{array}$ & & & $\otimes$ & & $\otimes$ & $\otimes$ & & & & \\
\hline $\begin{array}{c}\text { Straightness XY } \\
\text { according Y }\end{array}$ & & & $\otimes$ & $\otimes$ & $\otimes$ & & $\otimes$ & & & \\
\hline $\begin{array}{l}\text { Straightness } \mathrm{XY} \\
\text { according } \mathrm{X}\end{array}$ & & $\otimes$ & & $\otimes$ & $\otimes$ & & $\otimes$ & & & \\
\hline Flatness: Thin XY & $\otimes$ & $\otimes$ & $\otimes$ & $\otimes$ & $\otimes$ & & & $\otimes$ & & \\
\hline $\begin{array}{c}\text { Flatness: Thick } \\
\text { XY }\end{array}$ & $\otimes$ & $\otimes$ & $\otimes$ & $\otimes$ & $\otimes$ & & $\otimes$ & $\otimes$ & & \\
\hline $\begin{array}{c}\text { Angles/X, } \\
\text { Angles/Y }\end{array}$ & & & & & & & & & $\otimes$ & \\
\hline $\begin{array}{c}\text { Homogeneity } \\
\text { material }\end{array}$ & & & & & & & $\otimes$ & & & $\otimes$ \\
\hline
\end{tabular}

\section{F. Data and Results of Straightness and Flatness:}

For the first two following control cases, the diagonal line is the straightness direction/nominal ideal geometric element.

\section{1) According to $X Z$}

The $\mathrm{X}$ axis represents the nominal geometric element and carries the abscissa $\mathrm{Xi}$ points palpated from 0 to $100 \mathrm{~mm}$. The maximum and minimum value of the measurement deviation is $0.035 \mathrm{~mm}$ (right above the $\mathrm{X}$ axis) and $-0.03 \mathrm{~mm}$ (right below the $X$ axis). They intercept the default of the nominal form (Dfn). The $\mathrm{Z}$ axis carries the ordinates $\mathrm{Zi}$ (the measurement deviation), with $\mathrm{IT}=0.1 \mathrm{~mm}$ (between the extreme lines).

$$
Y=a X+b=0.0002 X+0.01+0.0187758775
$$

The values chosen according to $\mathrm{XZ}$ are the two extremes of the distance considered $(100 \mathrm{~mm}): 100^{\prime}-9^{\prime}-70^{\prime}=21+1=22 \mathrm{~mm}$ and $22+70=92 \mathrm{~mm}$.

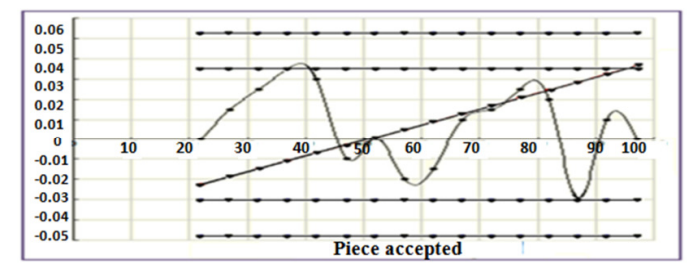

Fig. 10. Values and plot of the geometric control, test piece.

\section{2) According to $Y Z$}

The $\mathrm{Y}$ axis represents the nominal geometric element and carries the abscissa Yi points palpated from $0 \mathrm{~mm}$ to $110 \mathrm{~mm}$. The max and min value of the measurement deviation are $0.05 \mathrm{~mm}$ (right above the $\mathrm{X}$-axis) and $-0.015 \mathrm{~mm}$ (right below the $\mathrm{X}$-axis).

$$
Y=a X+b=0.000110511055454 X+0.022608511(2)
$$

The values chosen according to $\mathrm{YZ}$ are the two extremes of the distance considered $(110 \mathrm{~mm})$ : The first is: $15+2=17 \mathrm{~mm}$ and the second is: $15+84=108 \mathrm{~mm}$.

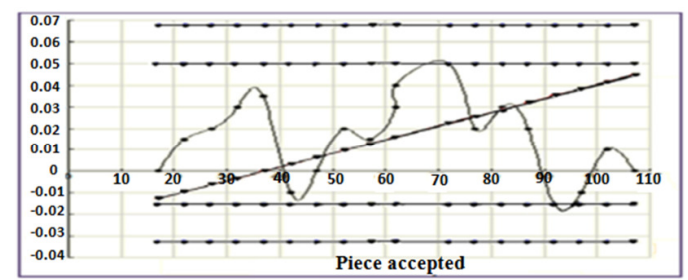

Fig. 11. Values and plot of graphs of the geometric control test piece

\section{3) According to $X Y$}

The diagonal line is the direction of straightness (associated line)/nominal ideal geometric element and is of the form:

$$
Y=a X+b Y+C=0.00191 X+0.0057852 Y+0.1050(3)
$$

The coordinates of the palpated points are projected onto the XY plane. The max and min values of the measurement deviation are the line above the $X$ axis $=0.05 \mathrm{~mm}$ and below the $X$ axis $=-0.015 \mathrm{~mm}$. Intercepting the (Dfn), for IT, Diff.sup $=+0.0680$ and Diff.sup $=-0.32$. Following the control process, the test piece is taken on a marble and calibrated the dial gauge in the "zero" position on the two end points of the dimensions to be checked.

\section{G. The Flatness Data}

Flatness measurements include devices to determine the surface state of a plane (the surface of the cover with the motor). It is to be noted that concerning the verification of the circularity, a work for a forthcoming, extended publication given the range of shapes and different diameters is underway. 


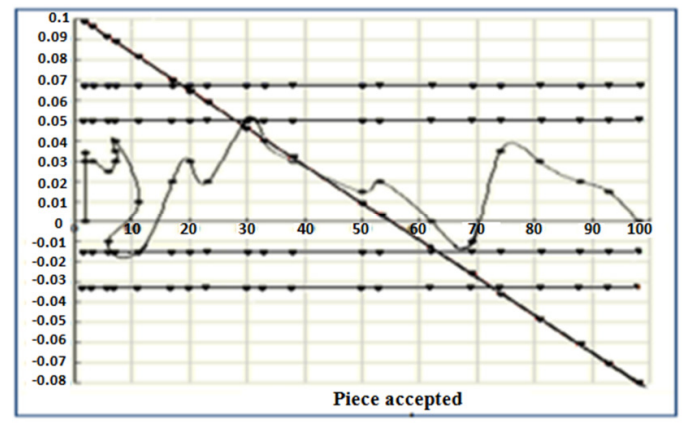

Fig. 12. Values and plot of the geometric control, test piece

\section{H. Processing Results}

The theoretical results (CAD plan) and the geometrically measured defects were compared for influencing factor definition. There is a correspondence with the correlation matrix by indicating the link (s) between measurements and influencing factor (s). Some measurements tend to provide a quantification of a single defect, but the analysis helped to determine the defects of machine and material origin.

\section{RESULTS INTERPRETATION}

The evolution of the ranges with the differences of measurements ' $\mathrm{e}$ ' are less dispersed and their distribution confirmed. Their concentration is within a tolerance range which can be characterized by two limits between 10 and $15 \mu \mathrm{m}$. The lack of straightness is defined by the minimum distance between two parallel straight lines that envelop this line (Figure 13)

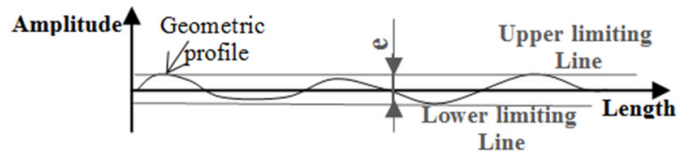

Fig. 13. Straightness defects on the contact surface

Following the recommendations of the standard [7], the straightness of a product is controlled by direct (tensile wire, ruler, marble, cylinder or optical beam) or indirect (level indicator etc.) measurement. Finally, shrinkage is identical to the settlement in the two dimensions of the XY plane, with a difference of the mean deviations on the two axes (Figure 14). Therefore, because of the uncertainty effect of the measurement deviations, it can be concluded that the test piece is accepted because it lies within the compliance zone (Figure $15)$.

\section{A. Conformity and Optimization of Measurements}

After selecting the measuring equipment, the question of the conformity of the measured dimensions is to be tackled. The uncertainty represents the space in which the part's dimension must lie relative to the value given by the instrument. When it is at the center of the tolerance interval and the uncertainty is low, no problems are encountered. On the other hand, if it is at the limit of the tolerance interval, there is a risk for the acceptance of non-conforming parts. If the measurement uncertainty is low, i.e. less than or equal to one quarter of the tolerance interval, the part is accepted. The method is advantageous when you have a good command of metrology and its investment will be valued because the elimination of parts will be scarce. Figure 16 illustrates the percentage between the measurement uncertainty and the tolerance interval.

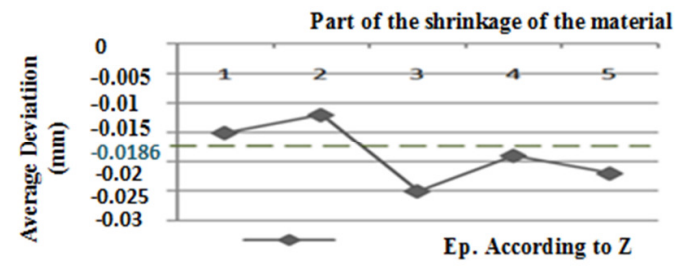

Fig. 14. Graph giving away the withdrawal of matter

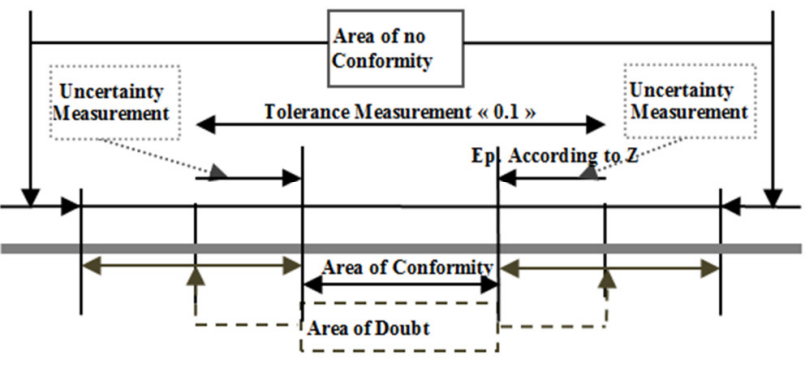

Fig. 15. Area of doubt and confirmation of the tolerance interval

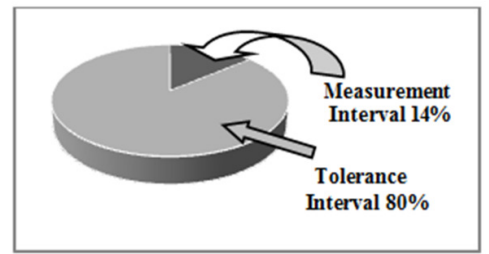

Fig. 16. Statistical representation by sector

It seemed essential to carry out a preliminary analysis in order to collect the necessary forms, knowing that this part will have to be fast and economical to manufacture. Conceiving it as a test makes possible to identify the origins of the defects. The approach that seems to be appropriate is the establishment of a correlation matrix, making possible to make the link between possible observations on the part (in metrology) and on the parameters related to the process and to the employed material. Its design makes possible to identify the origin of the deviations and to remove multiple interactions between the measurements and the parameters.

\section{CONCLUSION}

This work is a response to a real industrial need: setting up a qualification procedure adapted to fast prototyping machines (3D printers). Measurements of the same dimensions were conducted for five realized pieces. This study will be completed with the use of more test pieces. During measurements, effort was done to limit the influence of the environment, workforce, and method. The R \& D needs in this field are expressed by the implementation of a qualification approach by taking into account integrated geometric 
correctors. Quality is an essential variable for any company. The quality approach has become an indispensable management practice to achieve the objectives set. The adopted experimental procedure confirmed that all measurements are included in the interval of tolerance given by the designer. In perspective, other quality measurements (circularity, straightness, flatness, etc.) will be submitted in following articles to complete the qualification dimension. This study proposes a better product quality procedure that opens the way for a low-cost open access guarantee.

\section{REFERENCES}

[1] B. Belarbi, Qualification des Drocessus de Prototypage Rapide 'Cas d'imprimante 3D', MSc Thesis, Ecole Nationale Polytechnique d'Oran Maurice Audin, 2013 (in French)

[2] H. Bonnefoy, "Du prototypage rapidea la fabrication rapide", Technologie, Vol. 124, pp. 37-45, 2003 (in French)

[3] F. Hennebelle, Determination des Incertitudes de Mesures sur Machines a Mesurer Tridimensionnelles: Application Aux Engrenages, PhD Thesis, Arts et Metiers ParisTech, 2007 (in French)

[4] B. Rylands, T. Bohme, R. A. Gorkin III, J. P. Fan, T. Birtchnell, "3D Printing - To print or not to print? Aspects to consider before adoption A supply chain perspective", 22nd EurOMA Conference, Neuchatel, Switzerland, June 28-July1, 2015

[5] G. Cortes Robles, Management de l'Innovation Technologique et des Connaissances: Synergie Entre la Theorie TRIZ et le Raisonnement a Partir de Cas, PhD Thesis, Institut National Polytechnique de Toulouse, 2006 (in French)

[6] https://www.heidenhain.com/en_US/products/cnc-controls/

[7] http://fr.wikipedia.org/wiki/RepRap (in French)

[8] D. Scaravetti, P. Dubois, R. Duchamp, "Qualification of rapid prototyping tools: proposition of a procedure and a test part", The International Journal of Advanced Manufacturing Technology, Vol. 38, No. 7-8, 2008

[9] B. Belarbi, T. Benabdallah, G. Abdi, "Implementation of a New Dimensional Qualification (DQ) Method for an Open Access Fused Deposition Modeling 3D Printer", IREME, Vol. 10, No. 2, pp. 73-80, 2016

\section{AUTHORS PROFILE}

Boumediene Belarbi, was born in 1958, is a researcher and member in the Industrial Products and Systems Innovation Laboratory (IPSIL) at the National Polytechnic School in Oran (ENPO-Algeria) and a Lecturer at the Department of Electrical Engineering and Electronics and Industrial Engineering at the Faculty of Technology at the Abu Bekr Belkaid-Tlemcen University. Also he works on rapid prototyping, in the qualification of 3D Printers (FDM), and in innovation systems.

M. El Amine Ghernaout, was born in 1959, is a Professor and a $\mathrm{PhD}$ Holder in Thermal Machines and the head of ETAP Laboratory at the Faculty of Technology at the Abou Bekr Belkaid-Tlemcen University. He is currently a Lecturer at the Mechanical Engineering Department. He is involved in several research projects.

Tawfik Benabdallah, was born in 1960 , is a Professor and PhD Holder in Thermal Machines and the Head of the Industrial Products and Systems Innovation Laboratory (IPSIL) at the National Polytechnic School of Oran (ENPO-Algeria). He is currently a Lecturer at the Mechanical Engineering Department. He is involved in several research projects and international cooperations in innovation and prototyping. Also he is a member of many international scientific comities, and works in the field of energetic systems. 